\title{
Design Optimization of NDIR Automobile Exhaust Sensor Chamber Structure
}

\author{
Hongyan Chen, Zhibin Li, Bing Zhang, Jian Qu \\ College of Mechanical and Electrical Engineering \\ China Jiliang University \\ HangZhou, China \\ bbchy@163.com
}

\begin{abstract}
An optimized gas chamber structure is determined based on orthogonal experiment and numerical simulation combination method.The optimization of NDIR automobile exhaust sensor chamber structure includes three factors:gas chamber diameter, gas chamber length and opening way.By the experiment,it is shown that the optimized NDIR exhaust gas sensor has the advantage of good detection stability and fast response time.For example,the sensor detection stability is improved by $25.7 \%$ and the response time is improved by $38 \%$, when detected the main component of automobile exhaust $\mathrm{CO}_{2}(12.5 \%)$.
\end{abstract}

Keywords-automobile exhaust sensor;NDIR;gas chamber structure;orthogonal experiment;numerical simulation

\section{INTRODUCTION}

The automobile exhaust has become an important source of the air pollution and one of the main factor to influence the quality of city air environment[1].Thus,it's very important to strengthen the detection and the control of the automobile exhaust. Because the infrared spectrum absorption technology has the advantage of good selectivity 、 high sensitivity 、 fast response speed,so now measuring the automobile exhaust by infrared spectrum absorption technology has been a research hot spot in automobile exhaust testing field[2].The diatomic molecules have a particular absorption peak to the infrared light,which is used by infrared absorption technique.It can detect the gas concentration by Lambert-Beer's law[3].The schematic diagram of NDIR(non-dispersive Infrared ray) automobile exhaust sensor structure is showed in Figure 1,which mainly consists of light source 、 gas chamber 、 detector.Among them, the air chamber is one of the important components of the NDIR exhaust sensor structure and has huge influence on the detection stability as well as the response time of the sensor[4].

Liu, who designed a $95 \mathrm{~mm}$ length, $10 \mathrm{~mm}$ diameter cylindrical chamber structure, used the infrared absorption technique to detect the concentration of methane [5]; Wang designed a $80 \mathrm{~mm}$ length, $25 \mathrm{~mm}$ diameter cylindrical chamber structure, which used infrared spectral absorption to detect the methane concentration [6]; Ji designed a $100 \mathrm{~mm}$ length, $5 \mathrm{~mm}$ diameter cylindrical chamber structure, which used infrared spectral absorption to detect the $\mathrm{CO}, \mathrm{CO}_{2}, \mathrm{H}_{3} \mathrm{~N}$ concentration[7]. The optimization analytical articles of chamber structure are very rare in the research and development of NDIR automobile exhaust sensor. Therefore, in order to get the optimal combination of structural parameters and improve exhaust gas sensor test index values ,an optimized gas chamber structure was determined based on orthogonal experiment and numerical simulation combination method.The optimization of NDIR automobile exhaust sensor chamber structure parameters includes three factors:gas chamber diameter, gas chamber length and opening way.

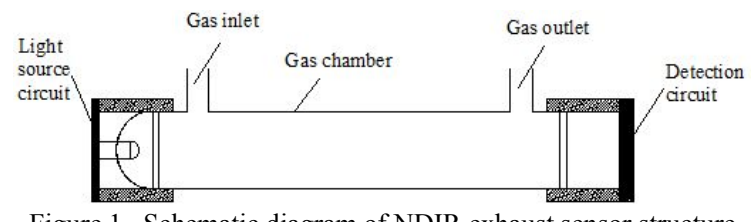

Figure 1. Schematic diagram of NDIR exhaust sensor structure

\section{PROgRAM OF ORThOgONAL TEST}

\section{A. Analysis of Indicator}

Lambert-Beer's law requires a uniform light-absorbing substance which is non-scattering system. The airflow velocity of internal points is different in the NDIR automobile exhaust sensor,which is evaluated by "uniformity coefficient" . The smaller the uniformity coefficient is, the more uniform the internal gas distribution is, which will help improve the detection stability and response time of automobile exhaust sensor.Select $\mathrm{N}$ measuring points in the internal gas chamber and measure each speed of the measuring points.

The arithmetic mean of speed:

$$
\bar{v}=\frac{\sum v_{i}}{n}
$$

The root mean square error:

$$
\sigma_{v}=\sqrt{\frac{\sum\left(v_{i}-\bar{v}\right)^{2}}{n}}
$$

The uniformity coefficient is defined as $\eta$ :

$$
\eta=\frac{\sigma_{v}}{\bar{v}}
$$

\section{B. Orthogonal Test Program}

Orthogonal experiment is aimed to complete the multifactor, multi-level optimization of the design work [8]. In this paper,the orthogonal experiment is designed about three factors:gas chamber diameter D, gas chamber length $\mathrm{L}$ and opening way $\mathrm{C}$ which influence automobile exhaust sensor chamber structure . Factors of chamber structure correspond to three kinds of level values, which is shown in Table 1.L9 $\left(3^{4}\right)$ is selected as the orthogonal test program, which has a total of nine tests, shown in Table 2.The schematic diagram of 
automobile exhaust sensor chamber structure size of three opening ways is shown in Figure 2.

TABLE I. LEVELS FOR EACH FACTOR

\begin{tabular}{|c|c|c|c|c|c|}
\hline Level & $\mathrm{D} / \mathrm{mm}$ & & $\mathrm{L} / \mathrm{mm}$ & \multicolumn{2}{|c|}{$\mathrm{C}$} \\
\hline 1 & 10 & & 60 & \multicolumn{2}{|c|}{$\begin{array}{l}\text { Single input single output } \\
\text { (upper left in,upper right out) }\end{array}$} \\
\hline 2 & 15 & & 80 & \multicolumn{2}{|c|}{$\begin{array}{c}\text { Single input single output } \\
\text { (upper left in,button right out) }\end{array}$} \\
\hline 3 & 25 & & 100 & \multicolumn{2}{|c|}{$\begin{array}{l}\text { Double input double output } \\
\text { (left in,right out) }\end{array}$} \\
\hline & \multirow[t]{2}{*}{ TABLE II. } & \multicolumn{4}{|c|}{ ORThogonal Test Program } \\
\hline & & $\mathrm{D}$ & & $\mathrm{L}$ & $\mathrm{C}$ \\
\hline 1 & & 1 & & 1 & 1 \\
\hline 2 & & 1 & & 2 & 2 \\
\hline 3 & & 1 & & 3 & 3 \\
\hline 4 & & 2 & & 1 & 2 \\
\hline 5 & & 2 & & 2 & 3 \\
\hline 6 & & 2 & & 3 & 1 \\
\hline 7 & & 3 & & 1 & 3 \\
\hline 8 & & 3 & & 2 & 1 \\
\hline 9 & & 3 & & 3 & 2 \\
\hline
\end{tabular}

(a)

(b)

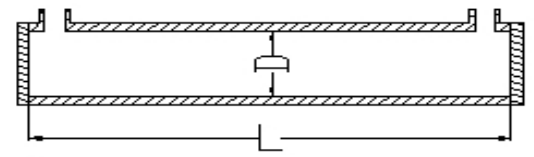

(c)
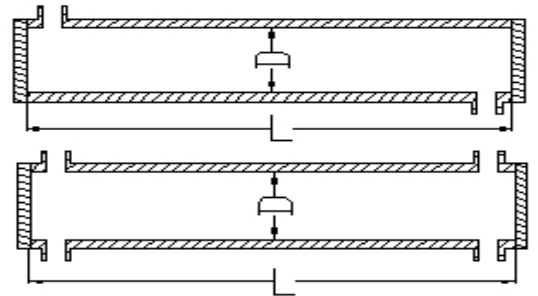

Figure 2. Schematic diagram of automobile exhaust sensor chamber structure size:(a) $\mathrm{C} 1$;(b)C2;(c)C3

\section{RESUlts OF NUMERICAL SimULATION}

\section{A. Results of Numerical simulation}

Numerical simulation is carried out by the simulation software FLUENT 6.3, which can combine extended Realizable $k-\varepsilon$ turbulence model with SIMPLE algorithm[9]. 9 results of numerical simulation to reflect model performance are listed in Table 3.Figure 3 shows the center sectional contours of velocity of cylindrical chamber in test 1 and test 3 .Figure 4 shows the center sectional velocity vectors of cylindrical chamber in test 1 and test 3.Figure 5 shows the center sectional flow chart of cylindrical chamber in test 1 and test 3 .According to such figures,we can conclude that the radial velocity difference in test 3 is smaller than test 1. What's more,the internal gas distributes uniformly with no turbulence ant its uniformity coefficient is 0.18 .

TABLE III. NUMERICAL SimUlation RESUlts

\begin{tabular}{cccccccccc}
\hline $\begin{array}{l}\text { Test } \\
\text { No. }\end{array}$ & 1 & 2 & 3 & 4 & 5 & 6 & 7 & 8 & 9 \\
\hline$\eta_{i}$ & 0.63 & 0.41 & 0.18 & 0.46 & 0.21 & 0.51 & 0.31 & 0.57 & 0.37 \\
\hline
\end{tabular}

(a)

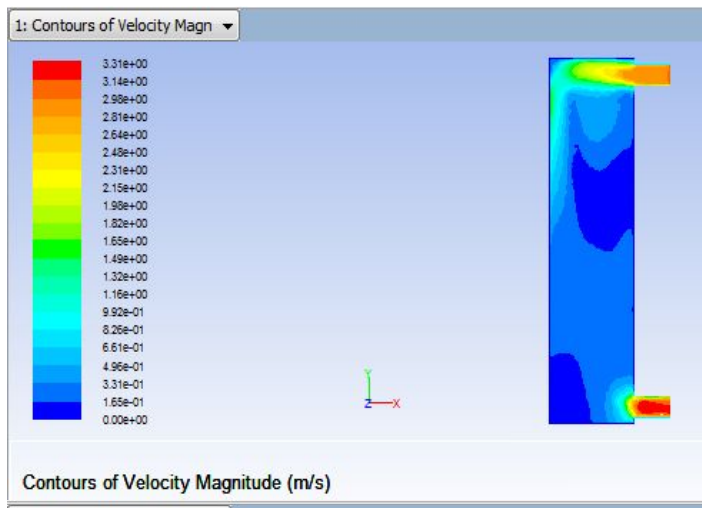

(b)

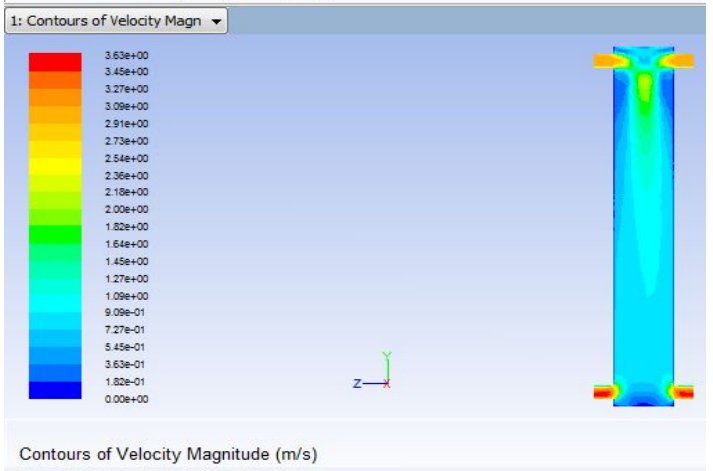

Figure 3. Center sectional velocity contours of cylindrical chamber: (a) test 1;(b) test 3

(a)

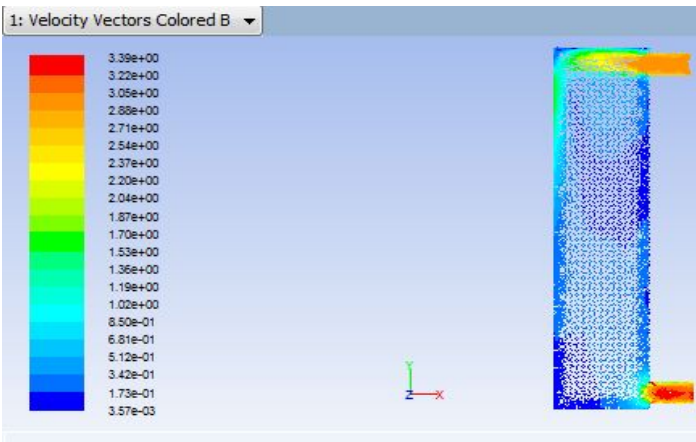

Velocity Vectors Colored By Velocity Magnitude $(\mathrm{m} / \mathrm{s})$

(b)

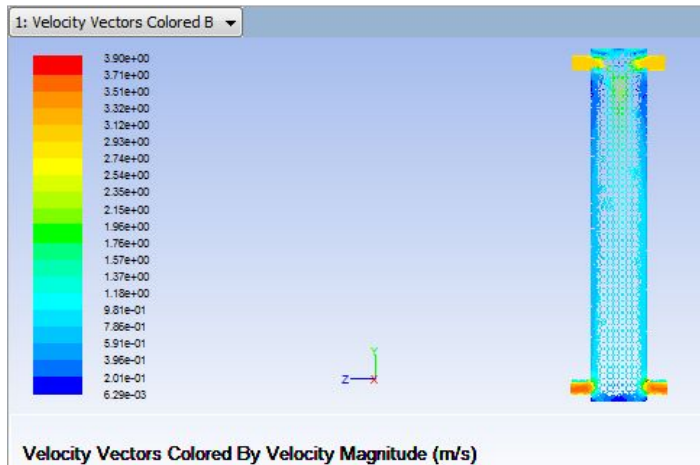

Figure 4. Center sectional velocity vectors of cylindrical chamber: (a) test $1 ;$ (b) test 3 
(a)

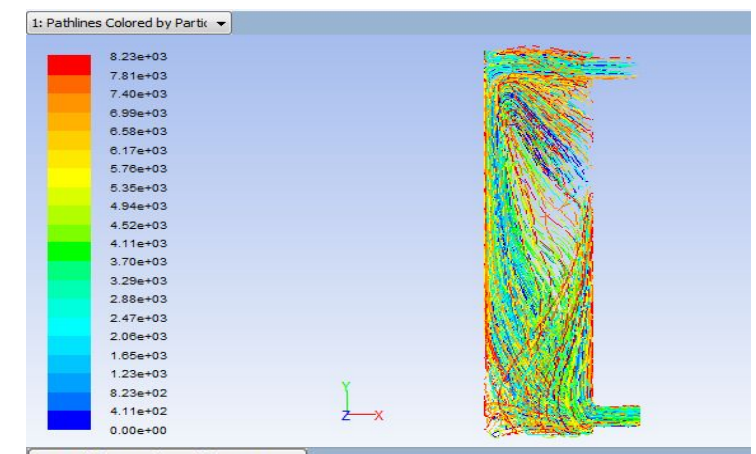

(b)

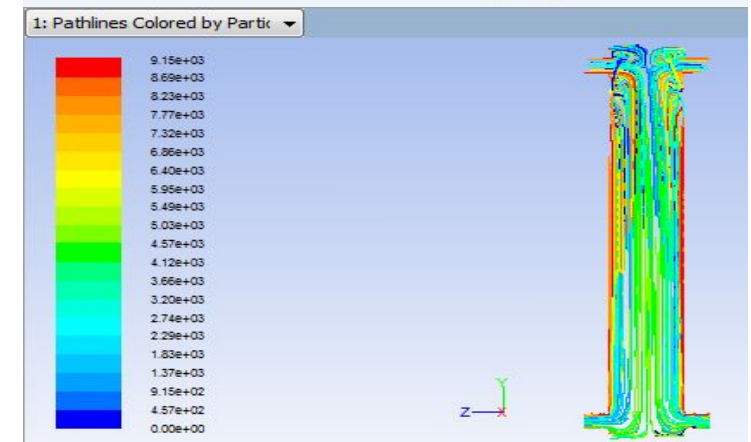

Figure 5. Center sectional flow chart of cylindrical chamber: (a) test $1 ;$ (b) test 3

\section{B. Analysis of Range}

In general, range has difference on different levels in the same factor, which shows that each factor's level has different impacts on the test results. According to the simulation results, we obtained the same factor's mean test indicators at different levels. The larger the average's range is,the bigger the influence on the factor level is. So the factor with the biggest range has the most apparent influence on the test result.In other words, this factor is the most important factor[10]. By the range analysis,we find that the ranges of three factors(D、L、 C)are $0.023 、 0.113 、 0.337$, which are shown in Table 4.Therefore, the most important factor which influences the test indicator is the opening way,followed by the gas chamber length,and the factor has the least important influence on the test indicator is the gas diameter.

TABLE IV. NUMERICAL SimULATION ANALYSIS

\begin{tabular}{ccccc}
\hline \multirow{2}{*}{ Analysis of indicator } & \multicolumn{3}{c}{ Factor } \\
\cline { 3 - 5 } & $\mathrm{K}_{1}$ & $\mathrm{D}$ & $\mathrm{L}$ & $\mathrm{C}$ \\
\cline { 2 - 5 } & $\mathrm{K}_{2}$ & 1.22 & 1.4 & 1.71 \\
& $\mathrm{~K}_{3}$ & 1.18 & 1.19 & 1.24 \\
& $\mathrm{k}_{1}$ & 0.407 & 1.06 & 0.7 \\
& $\mathrm{k}_{2}$ & 0.93 & 0.467 & 0.57 \\
& $\mathrm{k}_{3}$ & 0.417 & 0.397 & 0.413 \\
& $\mathrm{R}$ & 0.023 & 0.353 & 0.233 \\
& & & 0.113 & 0.337 \\
\hline
\end{tabular}

\section{Analysis of Variance}

The range analysis gives us the order of each complication' $\mathrm{s}$ influence on the test-index $\eta$.Meanwhile, the variance-analysis distinguishes between data fluctuation which caused by experimental conditions change and experimental error,estimating the error.By the variance calculating,we get the standard deviation of three three factors(D、L、C) are $0.001 、 0.073 、 0.011$. Through the F-test,we know the opening way is the relatively significant factor and the gas chamber length is the significant factor,but the gas chamber diameter is the non-significant factor.Through the range analysis, we can confirm the best optimal scheme combination is D1 、 L3 、 C3.Thus, the optimal gas chamber parameter is $\mathrm{D}(10 \mathrm{~mm}) 、 \mathrm{~L}(100 \mathrm{~mm}) 、 \mathrm{C}($ double input double output $)$.

\section{EXPERIMENT AND ANALYSIS}

According to the result of orthogonal experiment,we can get the optimization gas chamber structure parameters of NDIR automobile exhaust sensor.The detection principle of experiments in this paper is shown in Figure 6.In this paper,we contrast and analysis the optimization gas chamber structure of the sensor (has become the gas chamber sample)and the original gas chamber $(\mathrm{D} 10 \mathrm{~mm} 、 \mathrm{~L} 60 \mathrm{~mm} 、 \mathrm{C}$ single input single output).We choose the detection stability and the response time of the sensor as the analysis index,we also choose the automobile exhaust whose $\mathrm{CO}_{2}$ standard concentration is $12.5 \%$ to conduct 5 tests.Such results are listed in Table 5 .According to the Table 5,we can get the conclusion:the stability of the optimization sensor is improved by $25.7 \%$ and the response time is improved by $38 \%$.

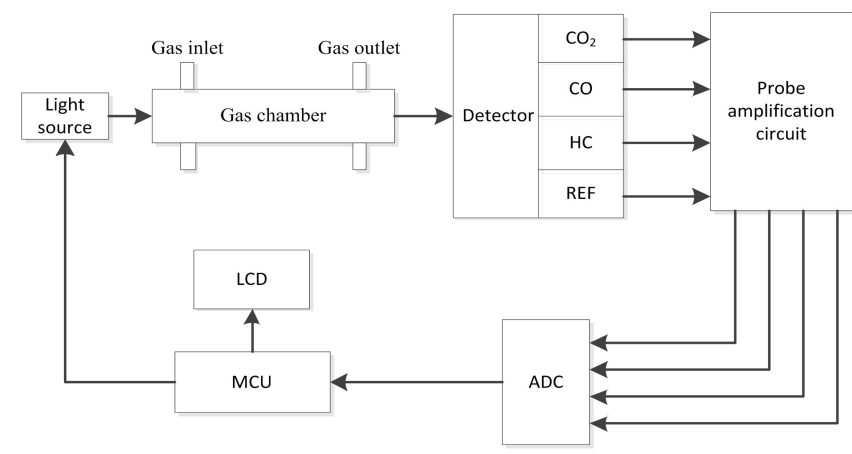

Figure 6. Schematic diagram of detection principle

TABLE V. EXPERIMENTAL RESUlts CONTRAST ANALYSIS

\begin{tabular}{ccccc}
\hline Test No. & $\begin{array}{c}\text { Optimized test } \\
\text { concentration } \\
\%\end{array}$ & $\begin{array}{c}\text { Before } \\
\%\end{array}$ & $\begin{array}{c}\text { Optimized } \\
\text { response time } \\
\mathrm{s}\end{array}$ & $\begin{array}{c}\text { Before } \\
\mathrm{s}\end{array}$ \\
\hline 1 & 12.43 & 12.35 & 3.0 & 4.1 \\
2 & 12.37 & 12.68 & 3.1 & 4.0 \\
3 & 12.57 & 12.42 & 3.0 & 4.3 \\
4 & 12.52 & 12.63 & 2.9 & 3.9 \\
5 & 12.63 & 12.33 & 3.0 & 4.4 \\
\hline
\end{tabular}

\section{CONCLUSION}

Be aimed at 3 structure parameters which influences the Performance of NDIR exhaust sensor:gas chamber diameter gas chamber length 、 opening way,we use orthogonal experiment to study 9 designed gas chamber structure models in numerical simulation. As a result,we acquire the order of each structure parameters which influences automobile exhaust sensor performances.We also confirm the optimized design scheme of the gas chamber structure.The contrast experiment shows :

(1) The stability of the optimization sensor is improved by $25.7 \%$ and the response time is improved by $38 \%$;

(2) It is feasible to conduct gas chamber sensor structure' $s$ optimal design by combining numerical simulation with 
orthogonal experimental.It provides theoretical basis to this optimal design.

\section{REFERENCES}

[1] An-qiu Chen. Automobile exhaust pollution and detection technology[J].Intelligence .2011(2).

[2] Ohann Mayrwöger, Peter Hauer, Wolfgang Reichl,etc. Modeling of Infrared Gas Sensors Using a Ray Tracing Approach[J].IEEE SENSORS JOURNAL, Vol.10, No.11, 2010, pp.1691-1698.

[3] You-wen Wang,Wen-qing Liu,Shi-mei Wang,etc.Non-dispersive infrared multi-component gas analysis system[J].Infrared and Laser Engineering, 2012,41(4):1062-1068.

[4] A. Sklorz, A. Schafer, W. Lang, Merging ethylene NDIR gas sensors with preconcentrator-devices for sensitivity enhancement, Sensors and Actuators B: Chemical170,2012,pp.21-27.
[5] Gang Liu,Ting Liang,etc.Design of direct gas chamber of infrared methane sensor[J].Industry and Mine Automation, 2013,39(3):31-35.

[6] Wen-cui Wang.Development of methane concentration detection instrument based on NDIR principle[D].Harbin:Harbin Institute of Technology, 2009.

[7] Xin-Ming JI,Fe-die WU,Jian-ye WANG,Quan LIU,Yi-ping HUANG .The Application of the Portable Infrared Absorption Sensor in Fire Detection[J].Chinese Journal of Sensors and Actuators,2005.

[8] Yun-yan Li,Chuan-rong Hu.Experimental design and data processing[M].Beijing:Chemical Industry Press, 2008.

[9] Fu-jun Wang. Computational fluid dynamics analysis[M].Beijing: Tsinghua University Press, 2004.

[10] Zhi-xi Li,Shuang-kui Du. Experimental design and statistical analysis Optimization[M].Beijing: Science Press, 2010. 